\title{
Efeito de um hidrolisado de proteínas de soro de leite e de seus peptídeos na proteção de lesões ulcerativas da mucosa gástrica de ratos
}

\author{
Effects of a whey protein concentrate and it's peptides in \\ the protection of ulcerative lesions at rat gastric mucosa
}

\author{
Maria Teresa Bertoldo PACHECO ${ }^{1}$ \\ Érica BIGHETTI² \\ Márcia ANTÔNIO² \\ João Ernesto de CARVALHO² \\ Caroline Filla ROSANELI ${ }^{3}$ \\ Valdemiro Carlos SGARBIERI ${ }^{3}$
}

\section{R E S U M O}

\section{Objetivo}

Avaliar a atividade do hidrolisado das proteínas de soro de leite bovino e uma fração de peptídeos de baixo peso molecular (peso molecular $\leq 1 \mathrm{kDa}$ ), na proteção do epitélio da mucosa do estômago de ratos Wistar adultos contra o processo ulcerativo, induzidos por três diferentes agentes.

\section{Métodos}

Nesse estudo foram utilizados os modelos de indução de úlcera pelo antiinflamatório indometacina (30mg/kg de peso), por etanol absoluto $\left(1 \mathrm{ml} /\right.$ animal) e por estresse causado por imobilização e frio $\left(4^{\circ} \mathrm{C} / 2 \mathrm{~h}\right) \mathrm{em} \mathrm{ratos}$ Wistar adultos.

\section{Resultado}

O hidrolisado protéico de soro de leite foi obtido por tratamento com pancreatina, ao grau de hidrólise de $20 \%$, e fracionado em membrana de fluxo tangencial com faixa de corte de 1kDa, para obtenção de uma fração contendo peptídeos de baixo peso molecular denominada peptídeos do hidrolisado protéico de soro $(\leq 1 \mathrm{kDa})$. A administração aguda do hidrolisado protéico de soro, de acordo com o modelo etanol, resultou em $65,5 \%$ de redução dos índices de lesões ulcerativas, sendo obtida 77,4\% de inibição em dose dupla.

\footnotetext{
1 Centro de Química de Alimentos e Nutrição Aplicada, Instituto de Tecnologia de Alimentos. Av. Brasil, 2880, 13070-178, Campinas, SP, Brasil. Correspondência para/Correspondence to: M.T.B. PACHECO.E-mail:<mtb@ital.sp.gov.br>.

${ }^{2}$ Centro de Pluridisciplinar de Pesquisas Químicas, Biológicas e Agronômicas e Departamento de Clínica Médica, Faculdade de Ciências Médicas, Universidade Estadual de Campinas. Campinas, São Paulo, Brasil.

3 Departamento de Alimentos e Nutrição, Faculdade de Engenharia de Alimentos, Universidade Estadual de Campinas. Campinas, SP, Brasil.
} 


\section{Conclusão}

O efeito citoprotetor dos peptídeos de baixo peso molecular foi mais elevado para o modelo de indução por antiinflamatório, em relação ao hidrolisado integral, tanto em dose única como em dupla $(53,1 \%$ e 71,6\% de redução dos índices de lesões ulcerativas, respectivamente). Não foi constatada atividade protetora em modelos de úlcera induzidos por estresse.

Termos de indexação: hidrolisados de proteínas; peptideos; ratos wistar; úlcera gástrica.

\section{A B S T R A C T}

\section{Objective}

To assess the ability of bovine whey protein hydrolysate and its low molecular weight fraction (molecular weight $\leq 1 \mathrm{kDa}$ ) to protect the gastric mucosa of rats against ulcerative process induced by three different agents.

\section{Methods}

Adult Wistar rats were subjected to the indomethacin-induced ulcer (30mg/kg body weigh), absolute ethanol (1m/lanimal) and immobilization and cold stress $\left(4^{\circ} \mathrm{C} / 2 \mathrm{~h}\right)$, models.

\section{Results}

Whey protein hydrolysate was obtained by treatment with pancreatin to a degree of hydrolysis of $20 \%$ and fractionated using a tangential flow membrane with a molecular weight cut-off of $1 \mathrm{kDa}$ to obtain the fraction containing low molecular weight peptides ( $\leq 1 \mathrm{kDa}$ ). In the ethanol-induced acute ulcer model (single dose), whey protein hydrolysate inhibited the gastric lesion index by $65.5 \%$ and the double dose resulted in a $77.4 \%$ inhibition.

\section{Conclusion}

For the anti-inflammatory model, the cytoprotective effect of low molecular weight peptides was stronger than that of total hydrolysate (53.1 and $71.6 \%$, ulcerative lesion index) for single and double dose, respectively. No mucosa cytoprotective activity was found for whey protein concentrate, whey protein hydrolysate or WPHP in the immobilization and cold stress model.

Indexing terms: protein hydrolysates; peptides; rats, Wistar; stomach ulcer.

\section{N T R O D U Ç Ã O}

Várias condições físicas e psicológicas, ocasionadas principalmente por estresse, estão relacionadas a causas de úlcera gástrica em modelos humanos e animais. A carbenoxolona sódica é uma droga com atividade antiulcerogênica comprovada, amplamente utilizada para tratamento de úlcera. Seu mecanismo de ação consiste em aumentar a síntese das prostaglandinas na mucosa gástrica, inibindo as enzimas que promovem seu catabolismo das prostaglandinas ${ }^{1,2}$. A cimetidina também é uma droga amplamente utilizada como agente anti-secretório gástrico na prevenção e tratamento de úlceras gástricas ${ }^{3}$.
As proteínas do soro de leite têm sido apontadas como nutrientes portadores de atividade funcional, capazes de modular algumas respostas fisiológicas do organismo animal. Evidências fornecidas por estudos realizados em diferentes modelos experimentais (animais, humanos e células in vitro), utilizando a proteína do soro de leite, têm comprovado a eficácia deste produto na modulação orgânica, como o aumento da capacidade imunomodulatória, aumento no combate a infecções e processos inflamatórios, ação antibacteriana e antiviral, estímulo da absorção e função intestinal, aumento da absorção de minerais, aumento da síntese de hormônios, ação anticancerígena, além do efeito citoprotetor a partir da promoção da síntese de glutationa ${ }^{4-9}$. 
A atividade funcional das proteínas do soro de leite tem sido correlacionada à sua capacidade em estimular a síntese de glutationa celular. Para vários pesquisadores o estímulo à síntese de glutationa depende da liberação de peptídeos contendo a seqüência glutamilcistina por ação das enzimas do trato digestório. Trabalhos publicados a partir da década de 80 têm relatado que a glutationa intracelular possui atividade protetora contra lesões das células da mucosa gástrica por intermédio de mecanismos de citoproteção ${ }^{10-12}$.

Embora as proteínas do soro de leite possuam elevada digestibilidade e sejam rapidamente absorvidas para a circulação sangüínea, sabe-se que os hidrolisados protéicos contendo peptídeos de pequeno tamanho, di e tripeptídeos, são absorvidos numa velocidade maior, tanto em relação às proteínas como aos aminoácidos livres ${ }^{13}$. Os hidrolisados, na forma de di e tripeptídeos, preservam melhor a estabilidade de alguns aminoácidos em processos de esterilização e estocagem, aumentando a solubilidade sem prejudicar a osmolaridade no produto final ${ }^{14,15}$. Portanto, uma vez que as proteínas concentradas e hidrolisadas sejam obtidas e conservadas sem desnaturação, os peptídeos, obtidos pela proteólise destas, podem ser capazes de conservar e ampliar sua atividade funcional estimulando a síntese de glutationa e sendo provavelmente metabolizados num período de tempo mais curto.

Neste trabalho avaliou-se a atividade protetora de proteínas hidrolisadas do concentrado protéico de soro de leite e uma fração do hidrolisado, contendo peptídeos de baixo peso molecular $(\leq 1 \mathrm{kDa})$, ao proteger as células da mucosa gástrica contra o processo ulcerogênico, utilizando-se três modelos diferentes de indução de úlcera. Os tratamentos foram comparados à atividade antiulcerativa do concentrado protéico de soro de leite.

\section{M É T O D O S}

Obtenção do hidrolisado protéico de soro de leite (HPS): para produção do hidrolisado foi utilizado o concentrado protéico de soro de leite (CPS) obtido de acordo com a metodologia descrita por Borges ${ }^{16}$. O CPS foi utilizado como substrato a $10 \%(\mathrm{p} / \mathrm{v})$ em água, e o sistema enzimático pancreatina (Sigma P-1750) na proporção E/S de 1/250 em pH 7,5, a temperatura de $37^{\circ} \mathrm{C}$. O grau de hidrólise final foi de $20 \%$, sendo monitorado pelo método do $\mathrm{pH}$-stat ${ }^{17}$. A inativação enzimática foi realizada pelo aquecimento a $85^{\circ} \mathrm{C}$ por 15 minutos, seguido por liofilização.

O hidrolisado de pancreatina liofilizado foi ressuspendido em água ultra pura ( $5 \% \mathrm{p} / \mathrm{v})$ e submetido a ultrafiltração em membrana de fluxo

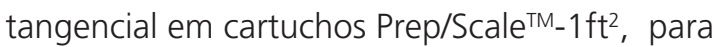
corte de peso molecular na faixa de $1 \mathrm{kDa}$ (hidrolisado de soro de leite fracionado - PHPS). O permeado contendo peptídeos de baixo peso molecular $(\leq 1 \mathrm{kDa})$ foi liofilizado e caracterizado quanto à composição de aminoácidos e distribuição do peso molecular dos peptídeos ${ }^{18}$.

Composição de aminoácidos: Determinada por hidrólise ácida $\left(\mathrm{HCl} 6 \mathrm{~N}, 110^{\circ} \mathrm{C}, 22 \mathrm{~h}\right)$ em analisador Dionex Dx-300, dotado de coluna de troca catiônica e reação colorimétrica pós-coluna com ninidrina. A quantificação foi realizada utilizando uma mistura padrão de aminoácidos (Pierce kit 22).

\section{Ensaio biológico}

Para a realização dos experimentos foram utilizados ratos Wistar machos, com peso corporal entre 300 - 400g. Os animais foram fornecidos pelo Centro de Bioterismo (CEMIB) da Universidade Estadual de Campinas (Unicamp) e utilizados nos experimentos após o período mínimo de sete dias de adaptação ao biotério, com ciclo de claro-escuro de 12 horas e temperatura ambiente de $20^{\circ} \mathrm{C}$, com água e ração ad libitum. O protocolo experimental foi aprovado pelo Comitê de Ética para Pesquisas Animais da Unicamp, em concordância com os princípios em pesquisa animal adotado pelo Colégio Brasileiro de Experimentação Animal (COBEA). 
Utilizaram-se grupos de 7 animais para os diferentes modelos de indução de úlcera. Para o tratamento em dose única (tratamento agudo), todos os ratos foram mantidos em jejum por 24 horas antes da administração via oral (por gavagem) dos tratamentos correspondentes. Os animais receberam uma dose $(1000 \mathrm{mg} / \mathrm{kg} /$ peso corpóreo) das soluções teste (CPS, HPS e PHPS) e salina. Para o tratamento em dose repetitiva os ratos, após terem recebido a primeira dose das soluções teste e salina, foram colocados em dieta comercial por 8 horas, seguida de jejum por 16 horas antes de receber a segunda dose das respectivas soluções teste $(2 \times 1000 \mathrm{mg} / \mathrm{kg}), 30$ minutos antes da indução da úlcera pelos diferentes modelos.

\section{Índice de lesões ulcerativas (ILU)}

Foram utilizados três modelos de indução de úlcera: antiinflamatório, etanol e estresse causado por imobilização e frio. O índice de lesões ulcerativas (ILU), determinado após aplicação dos protocolos referentes aos modelos de indução, foi calculado por meio da somatória dos parâmetros abaixo, de acordo com a metodologia descrita por Gamberini19; até 10 petéquias: 1 ponto; até 20 petéquias: 2 pontos; até 30 petéquias: 3 pontos; úlceras de até $1 \mathrm{~mm}$ : ${ }^{*} \mathrm{n} \times 2{ }^{*}{ }^{*} \mathrm{n}=$ número de lesões encontradas); úlceras maiores que $1 \mathrm{~mm}$ : ${ }^{*} n \times 3$ ( ${ }^{*} n=$ número de lesões encontradas); hemorragia: 1 ponto; perda de pregas: 1 ponto; perda da coloração: 1 ponto.

Para a determinação da porcentagem de redução do ILU apresentados pelos grupos tratados em relação ao grupo controle, foi utilizada a seguinte fórmula:

\section{Média controle - média tratado Média controle $\times 100$}

O modelo de úlcera gástrica, induzida por indometacina, foi utilizado para a determinação da $\mathrm{DE}_{50}$, utilizando os valores citados por Rosaneli et al. ${ }^{20}$ :
Modelos de indução de úlcera gástrica por antiinflamatório (indometacina): o ensaio foi conduzido com grupos de sete animais submetidos a cinco tratamentos diferentes. Para o controle negativo e positivo foram utilizadas solução de $\mathrm{NaCl}$ 0,9\% (10ml/kg/peso corpóreo) e suspensão aquosa de cimetidina (100mg/kg/peso corpóreo), respectivamente. O fluxograma da Figura 1 ilustra a metodologia utilizada. O concentrado protéico de soro (CPS), HPS e PHPS foi ressuspendido em solução salina na dose de $1000 \mathrm{mg} / \mathrm{kg}$ de peso. Após 30 minutos da gavagem cada animal recebeu uma injeção subcutânea de suspensão aquosa de indometacina $(30 \mathrm{mg} / \mathrm{kg} /$ peso corpóreo), segundo metodologia de Morimoto ${ }^{21}$. Transcorridas quatro horas os animais foram sacrificados por deslocamento cervical e os estômagos retirados para contagem e avaliação das lesões (ILU).

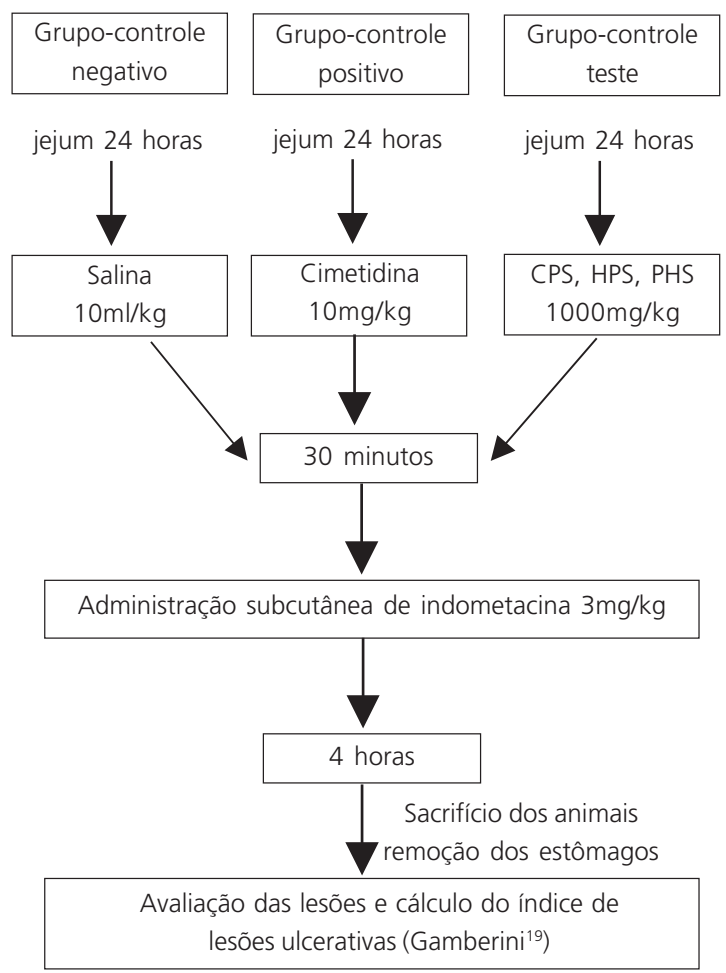

Figura 1. Indução de úlcera por antiinflamatório nos grupos de controle positivo (cimetidina), negativo (salina) e testes (CPS, HPS, PHPS), com dose única de tratamento prévio. 
Indução de úlcera por etanol: foram realizados cinco tratamentos $(n=7)$; controle negativo utilizou-se solução salina $0,9 \%(10 \mathrm{ml} / \mathrm{kg} /$ peso corpóreo), como controle positivo a carbenoxolona (200mg/kg) e outros três grupos receberam o CPS, HPS e PHP (1 000 mg/kg/peso corpóreo). Todos os animais após 30 minutos da gavagem, com o respectivo tratamento, receberam via oral $1,0 \mathrm{ml}$ de etanol absoluto, de acordo com a metodologia descrita por Robert ${ }^{22}$. Após uma hora da administração do etanol, os animais foram sacrificados e os estômagos retirados para contagem das lesões e cálculo do ILU19.

Indução da úlcera por estresse à imobilização e ao frio: neste experimento, após jejum de 24 horas, cada grupo $(n=7)$ de animais recebeu via oral, por gavagem, o tratamento correspondente. Tratou-se um dos grupos com solução salina no volume de $10 \mathrm{ml} / \mathrm{kg}$ (controle negativo), outro grupo com suspensão aquosa de cimetidina, na dose de $100 \mathrm{mg} / \mathrm{kg}$ (controle positivo) e os outros três grupos receberam as soluções testes na dose de $1000 \mathrm{mg} / \mathrm{kg}$, diluídas em solução salina. Os animais tiveram suas patas imobilizadas e as gaiolas foram deixadas em câmara fria a temperatura de $4^{\circ} \mathrm{C}$ por duas horas, segundo metodologia descrita por Levine ${ }^{23}$. Posteriormente os animais foram sacrificados e o número de lesões no estômago avaliado para o cálculo do ILU19.

Quanto à análise estatística, os resultados foram submetidos à análise de variância (ANOVA) e ao teste de Duncan ao nível de 95\% de confiabilidade, utilizando o programa Statistica $6.0^{\circledR 24}$.

\section{RESULTADOS E DISCUSSÃO}

O fracionamento do hidrolisado (HPS) de proteínas do soro de leite, por meio de membrana Prep-Scale com corte na faixa de $1 \mathrm{kDa}$ de peso molecular, teve por finalidade concentrar os peptídeos de baixo peso molecular e procurar identificar nessa fração a presença de peptídeos bioativos. De acordo com trabalhos da literatura25, as proteínas de soro de leite, hidrolisadas pelo sistema pancreatina num grau de hidrólise de $20 \%$, apresentam, aproximadamente, $90 \%$ do seu conteúdo constituído por peptídeos com peso molecular inferior a $1 \mathrm{kDa}$.

A composição aminoacídica da matéria prima original (CPS), do hidrolisado (HPS) e sua fração, contendo peptídeos de baixo peso molecular (PHPS), encontram-se na Tabela 1. De um modo geral os aminoácidos predominantes foram: o ácido aspártico, treonina, ácido glutâmico e lisina. Destacam-se o elevado conteúdo de aminoácidos ramificados, o baixo conteúdo de aminoácidos aromáticos e a proporção de 1:1 entre a cisteína e metionina nas diferentes amostras. O procedimento de hidrólise modificou apenas o conteúdo dos aminoácidos tirosina e histidina, em relação ao concentrado de soro de leite. O procedimento de ultrafiltração para obtenção da amostra PHPS resultou no aumento de alguns aminoácidos, tais como: ácido aspártico, glutamina, leucina e isoleucina e redução acentuada da histidina e arginina.

Tabela 1. Composição em aminoácidos do hidrolisado protéico de soro de leite (CPS), soro de leite hidrolisado (HPS) e hidrolisado de soro fracionado (PHPS).

\begin{tabular}{lrrr}
\hline Aminoácidos (g/100g prot) & \multicolumn{1}{c}{ CPS } & \multicolumn{1}{c}{ HPS } & \multicolumn{1}{c}{ PHPS } \\
\hline Asp & 10,50 & 10,71 & 10,57 \\
Thr & 6,88 & 7,17 & 6,48 \\
Ser & 5,53 & 5,48 & 5,14 \\
Glu & 17,81 & 18,36 & 18,77 \\
Pro & 5,97 & 5,95 & 5,64 \\
Gly & 1,79 & 1,76 & 1,75 \\
Ala & 4,75 & 4,71 & 5,32 \\
Cys & 2,45 & 2,08 & 2,07 \\
Val & 5,42 & 5,07 & 5,70 \\
Met & 2,46 & 1,98 & 2,11 \\
Ile & 5,69 & 5,31 & 6,80 \\
Leu & 10,55 & 10,53 & 11,49 \\
Tyr & 3,14 & 2,98 & 2,48 \\
Phe & 3,44 & 3,23 & 3,70 \\
Lys & 9,97 & 9,82 & 8,64 \\
His & 2,54 & 1,63 & 2,49 \\
Arg & 1,56 & 1,86 & 0,90 \\
\hline
\end{tabular}

Trp (Triptofano) é destruído na hidrólise ácida da proteína. 
Com o objetivo de conhecer melhor a distribuição dos peptídeos presentes no hidrolisado integral e sua fração de baixo peso molecular, foi realizada cromatografia de exclusão molecular na qual os peptídeos foram separados por faixas, de acordo com a quantidade de resíduos de aminoácidos. A análise do perfil de peptídeos revelou diferenças quanto à distribuição dos peptídeos em função do peso molecular. A fração com peptídeos de baixo peso molecular (PHPS) apresentou, aproximadamente, $60 \%$ dos peptídeos entre 2 a 7 resíduos de aminoácidos (Figura 2).

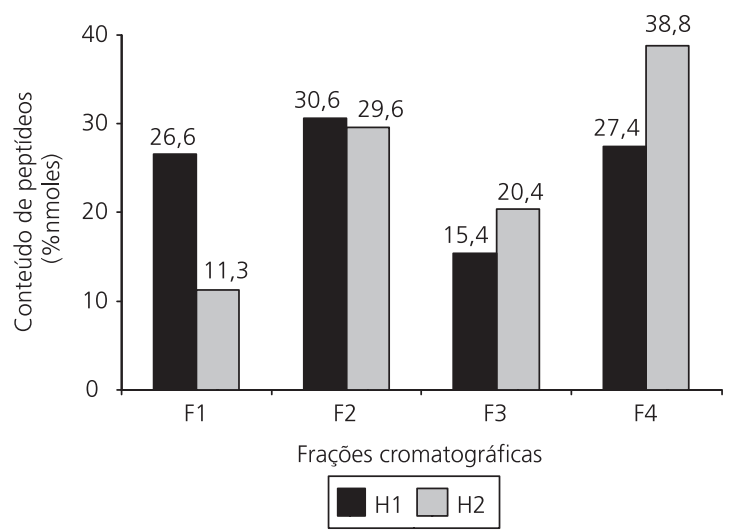

Figura 2. Perfil da distribuição dos peptídeos por faixa de peso molecular.

F1 = peptídeos com mais de 7 resíduos de aminoácidos; F2= peptídeos contendo entre 4 e 7 resíduos de aminoácidos; $\mathrm{F} 3$ = peptídeos contendo entre 2 e 3 resíduos de aminoácidos e F4= aminoácidos livres. Os valores estão expressos em porcentagem de nmoles e representam a média de triplicatas. $\mathrm{H} 1=$ hidrolisado integral e $\mathrm{H} 2=$ peptídeos com peso molecular abaixo de $1 \mathrm{KDa}$.

A maior diferença do PHPS em relação ao hidrolisado integral reside na faixa de peso molecular dos peptídeos acima de 7 aminoácidos, o quais foram predominantes para o HPS. Portanto, observou-se que a fração de baixo peso molecular em relação ao teor de di/tri-peptídeos (F3), aminoácidos livres (F4) e resíduos superiores a 7 aminoácidos (F1). A porcentagem dos peptídeos contendo entre 4 a 7 resíduos foi similar (F2).

Considerando o peso molecular médio dos aminoácidos em torno de 110 Daltons, as frações que contêm até 7 resíduos de aminoácidos perfazem cerca de $75,0 \%$ do hidrolisado integral e $90,0 \%$ do hidrolisado fracionado ( $\leq 1 \mathrm{kDa}$ ) e correspondem ao valor máximo de, aproximadamente, 800Da. Comparando estes valores com os descritos por Gonzáles-Tello25, verifica-se, no hidrolisado, a presença de um conteúdo de $26,6 \%$ de peptídeos com mais de 7 resíduos de aminoácidos, não descartando a semelhança entre os resultados (aproximadamente 25,0\%). Em trabalho anterior, realizado com proteínas de soro de leite hidrolisadas com pancreatina, a 20,0\% de grau de hidrólise, verificou-se a presença de um residual de $4,0 \%$ de proteínas intactas ${ }^{26}$, as quais, provavelmente, se encontram inseridas no percentual da fração F1 .

Os dados da Figura 2 mostram que o sistema enzimático pancreatina gerou no hidrolisado uma concentração bastante elevada de aminoácidos livres. Isso, provavelmente, se deve ao fato desse sistema conter, além de endoproteases (tripsina, quimotripsina), as carboxipeptidases, que são exoproteases, responsáveis pela maior liberação de aminoácidos livres. Conseqüentemente, quando o hidrolisado é fracionado, o teor de aminoácidos livres torna-se mais concentrado (10\%) em detrimento à fração com mais de 7 resíduos de aminoácidos.

Em relação aos ensaios biológicos, no modelo de úlcera induzida pela indometacina (antiinflamatório), observa-se (Tabela 2) que os valores de redução do ILU, para os tratamentos à base de soro de leite em dose única, já apresentaram um efeito protetor $(p<0,01) \mathrm{em}$ relação ao controle negativo (salina). A administração dos tratamentos CPS, HPS e PHPS em dose dupla resultou num efeito mais acentuado em proteger a mucosa, principalmente para o PHPS (Tabela 2), no qual a redução do ILU não diferiu $(p<0,01)$ do controle positivo (cimetidina).

No modelo de úlcera induzida por etanol o CPS apresentou uma porcentagem de redução do ILU de $38,2 \%$ e 69,24\%, para administração em dose única e dose dupla, respectivamente, 
Tabela 2. Resultados da porcentagem de redução do índice de lesões ulcerativas (ILU), utilizando o concentrado protéico de soro de leite (CPS), o concentrado hidrolisado (HPS) e fração do hidrolisado menor de 1 kDa (PHPS), em úlceras induzidas por indometacina, utilizando modelos agudo e repetitivo.

\begin{tabular}{lccc}
\hline $\begin{array}{l}\text { Modelo de } \\
\text { indução }\end{array}$ & Tratamento & ILU $^{\mathbf{a}}(\%)$ & $\begin{array}{c}\text { Redução } \\
\text { ILU(\%) }\end{array}$ \\
\hline Indometacina & CPS $^{\mathbf{c}}$ & $31,00 \pm 6,51^{* *}$ & 44,0 \\
Dose única $^{\mathbf{b}}$ & HPS $^{\mathbf{d}}$ & $31,50 \pm 10,80^{* *}$ & 43,0 \\
& PHPS & $29,20 \pm 15,23^{* *}$ & 47,2 \\
& Cimetidina & $14,25 \pm 5,92^{* *}$ & 74,2 \\
Indometacina & Salina & $55,36 \pm 16,24$ & \\
Dose dupla & CPS & $49,50 \pm 11,29^{* *}$ & 40,6 \\
& HPS & $32,80 \pm 9,20^{* *}$ & 60,7 \\
& PHPS & $22,80 \pm 10,73^{* *}$ & 73,6 \\
& Cimetidina & $17,50 \pm 9,38^{* *}$ & 79,0 \\
& Salina & $83,45 \pm 20,64$ & \\
\hline
\end{tabular}

a Índice de lesões ulcerativas; 'bporcentagem de redução das lesões ulcerativas; 'concentrado protéico de soro de leite; ${ }^{\mathbf{d}}$ concentrado de soro hidrolisado, ${ }^{e}$ peptídeos do hidrolisado de soro de leite. ANOVA (1) $\mathrm{F}_{(4,28)}=8,9, p<0,01$. Duncan $* * p<0,01$, em referência a salina; ANOVA $^{(2)} F_{(3,30)}=44,15 p<0,05$. Duncan ${ }^{* *} p<0,05$, em referência a salina.

Tabela 3. Resultados da porcentagem de inibição de lesões ulcerativas (ILU), utilizando o concentrado protéico de soro de leite (CPS), o concentrado hidrolisado (HPS) e a fração do hidrolisado menor de 1 kDa (PHPS), em úlceras induzidas por etanol, utilizando modelos agudo e repetitivo.

\begin{tabular}{|c|c|c|c|}
\hline $\begin{array}{l}\text { Modelo de } \\
\text { indução }\end{array}$ & Tratamento & ILUa $(\%)$ & $\begin{array}{c}\text { Inibiçãob } \\
\text { ILU(\%) }\end{array}$ \\
\hline & CPS $^{c}$ & $58,83 \pm 19,00^{\mathbf{b} * * *}$ & 38,2 \\
\hline Etanol & $\mathrm{HPS}^{d}$ & $32,80 \pm 4,92^{c * * *}$ & 57,0 \\
\hline \multirow[t]{4}{*}{ Dose única ${ }^{1}$} & PHPS & $29,20 \pm 11,56^{c * * *}$ & 69,3 \\
\hline & Carbenoxolona & $13,73 \pm 4,13^{d * * *}$ & 85,5 \\
\hline & Salina & $95,20 \pm 12,14^{a}$ & \\
\hline & CPS $^{c}$ & $30,50 \pm 9,95^{\mathbf{b} * * *}$ & 69,2 \\
\hline Etanol & HPS $^{d}$ & $21,60 \pm 4,70^{\mathbf{b} * * *}$ & 75,1 \\
\hline \multirow[t]{3}{*}{ Dose dupla ${ }^{2}$} & PHPS & $35,28 \pm 11,62^{\mathbf{b} * * *}$ & 64,6 \\
\hline & Carbenoxolona & $15,09 \pm 4,30 c * * *$ & 84,9 \\
\hline & Salina & $99,70 \pm 14,44^{a}$ & \\
\hline
\end{tabular}

a Índice de lesões ulcerativas; ${ }^{b}$ porcentagem de inibição das lesões ulcerativas, ${ }^{c}$ concentrado protéico de soro de leite, ${ }^{\mathbf{d}}$ concentrado de soro hidrolisado, ${ }^{\mathbf{e}}$ hidrolisado de soro de leite fracionado. ANOVA (1) $F_{(4,28)}=8,9, p<0,01$. Duncan ${ }^{* *} p<0,01$, em referência a salina; ANOVA $^{(2)} \mathrm{F}_{(3,30)}=44,15 p<0,05$. Duncan** $p<0,05$, em referência a salina.

indicando um efeito protetor cumulativo para a amostra. Os tratamentos à base de hidrolisados
(HPS e PHPS) foram capazes de reduzir o número de lesões ulcerativas em, aproximadamente, $75,0 \%$ (dose dupla), estatisticamente semelhante à carbenoxolona (84,9\% de redução ILU). Os resultados da porcentagem de redução do ILU para o modelo etanol podem ser observados na Tabela 3.

O etanol é considerado um agente irritante da mucosa gástrica, o qual destrói a camada de muco e o bicarbonato, que atuam na proteção da mucosa gástrica contra o ácido clorídrico e outros agentes agressores. O etanol atua bloqueando a citoproteção gástrica por precipitação das proteínas, liberação de radicais livres e redução da concentração de compostos sulfidrilas nas células da mucosa. Pode-se considerar que o efeito protetor, tanto das proteínas hidrolisadas como dos peptídeos do soro de leite provavelmente, está correlacionado com a elevada concentração de aminoácidos sulfurados presentes nas amostras, os quais são considerados limitantes na síntese da glutationa. No caso do hidrolisado fracionado, cujos peptídeos possuem elevada concentração de fragmentos protéicos com número diminuído de resíduos de aminoácidos, a absorção seria facilitada, permitindo a absorção destes numa velocidade maior em relação às proteínas íntegras e fragmentos de maior tamanho. A síntese destes compostos, em velocidade aumentada, poderia, conseqüentemente, ocasionar disponibilidade maior dos compostos sulfidrilas para a síntese de glutationa e, desta forma, contribuir para uma proteção mais rápida e eficiente da mucosa contra agentes ulcerogênicos.

Para o modelo de úlcera induzida pelo estresse, os resultados da contagem dos índices de lesões ulcerativas não apresentaram diferenças em relação ao controle negativo (salina), indicando que para este modelo de indução de úlcera, as amostras testes não apresentaram nenhum efeito enquanto moduladores da proteção das células epiteliais da mucosa dos animais. 
Para os modelos de indução de úlcera por antiinflamatório e etanol, o comportamento do hidrolisado fracionado foi similar (Tabelas 2 e 3), sendo eficiente já na primeira dose e conservando e/ou ampliando seu efeito protetor em dose dupla. O mecanismo pelo qual os hidrolisados expressam a atividade citoprotetora, provavelmente está relacionado ao conteúdo de aminoácidos sulfurados e modulação da síntese e concentração de glutationa celular pelos animais que receberam os tratamentos.

\section{O N CLUSÃ O}

Nas condições utilizadas foram obtidos dois produtos com propriedades funcionais fisiológicas ativas: o hidrolisado de soro de leite tratado com pancreatina e uma fração do hidrolisado contendo peptídeos de peso molecular abaixo de $1 \mathrm{kDa}$. A composição de aminoácidos no CPS, HPS e PHPS mostrou que não há grandes alterações na composição em função dos tratamentos utilizados, com exceção da redução acentuada da histidina e arginina no PHPS.

No modelo de úlcera induzida por antiinflamatório, em dose aguda, o efeito do CPS e fração de baixo peso molecular do hidrolisado foi similar. Na dose repetitiva o hidrolisado fracionado de baixo peso molecular foi mais efetivo em inibir o ILU (77\%), igualando-se ao controle positivo da droga antiinflamatória cimetidina. No modelo de úlcera induzida por etanol o hidrolisado fracionado revelou um potencial elevado de citoproteção gástrica já na primeira dose (dose única), conservando a atividade na dose repetitiva. O HPS mostrou-se eficiente apenas na dose repetitiva, igualando-se ao CPS.

A atividade citoprotetora do CPS, do hidrolisado (HPS) e sua fração contendo peptídeos de baixo peso molecular pode ser atribuída à presença de elevado conteúdo de compostos sulfidrilas, os quais, provavelmente, serviram de substrato para síntese de glutationa pelas células da mucosa gástrica.

\section{A GRADECIMENTOS}

À FAPESP pela concessão da bolsa de pós-doutorado e auxílio de pesquisa Processo 98/03120-5, e ao CPQBA pela utilização de suas instalações para realização dos testes biológicos.

\section{RE FER Ê N CIAS}

1. Das D, Banerjee RK. Effect of stress on the antioxidant enzymes and gastric ulceration. Mol Cell Biochem. 1993; 125(2):115-25.

2. Lewis DA, Hanson PJ. Anti-ulcer drugs of plant origin. Prog Med Chem. 1991; 28:201-31.

3. Dias PC, Flogio MA, Possenti A, Carvalho JE. Antiulcerogenic activity of crude hidroalcoholic extract of Rosmarinus officinalis $L$. J. Ethnopharmacol. 2000; 69(1):57-62.

4. Bounous G, Gold P. The biological activity of undenatured dietary whey proteins: role of glutathione. Clin Invest Med. 1991; 14(4):296-309.

5. Bounous G, Baruchel S, Falutz J, Gold P. Whey proteins as a food supplement in HIV-seropositive indivuduals. Clin Invest Med. 1993; 16(3):204-9

6. McIntosh GH, Royle PJ, Le Leu PK. Whey protein as functional food ingredients? Int Dairy J. 1998; 8:425-34

7. Fonseca LM, Fonseca CSP, Brandão SCC. Propriedades anticarcinogênicas de componentes do leite. Ind Latic. 1999; 21:31-4.

8. Brink W. Fighting cancer with whey. Life Ext Report. 1997; 12:13-5.

9. Sgarbieri VC, Pacheco MTB. Alimentos funcionais fisiológicos. Braz J Food Technol. 1999; 2:7-19.

10. Loguercio C, Taranto $D$, Beneduce $F$, del Vecchio Blanco C, de Vicentiis A, Nardi G, et al. Glutathione prevents ethanol induced gastric mucosal damage and depletion of sulfidryl compounds in human. Gut. 1993; 34(2):161-5.

11. Hiroishi H, Shimada T, Ivey KJ, Terano A. Role of anti-oxidant defenses against ethanol-induced damage in cultures of rat gastric epithelial cells. J Pharm Exp Therapeutic. 1999; 289:103-9.

12. Robert A, Eberle O, Kaplowitz $N$. Role of gluthatione in gastric mucosal cytoprptetion. Am J Physiol. 1984; 247:296-304.

13. Grimble RF, Grimble GK. Immunonutrition: Role of sulfur amino acids, related amino acids, and polyamines. Nutrition. 1998; 14(7-8):605-10.

14. Adibi AS. Intestinal transport of dipeptides in man: relative importance of hydrolysis and intact absorption. J Clin Invest. 1987; 50(11):2266-75. 
15. Amaya-Farfan J, Pacheco MTB. Amino acids: (A) properties and occurrence. In: Finglas BC, Trugo PL. Encyclopedia of food sciences and nutrition. 2nd ed. London; 2003. p.146-53.

16. Borges PFZ, Sgarbieri VC, Dias NGP, Jacobucci HB, Pacheco MTB, Baldini V LS. Produção piloto de proteínas de leite bovino: composição e valor nutritivo. Braz J Food Technol. 2001, 52:1-8.

17. Adler-Nissen J. Methods in Food proteins Hydrolysis. In: Enzymatic hydrolysis of food proteins. London: Elsevier; 1986. p.110-31.

18. Silvestre MPC, Hamon M, Yvon M. Analysis of protein hydrolysates. 1. Use of poly(2-hydroxyethilaspartamide)-silica column in size-exclusion chromatography for the fractionation of casein hidrolysates. J Agric Food Chem. 1984; 42:2778-82.

19. Gamberini MT, Skorupa LA, Souccar C, Lapa AJ. Inhibition of gastric secretion by a water extract from Baccharis triptera, Mart. Mem Inst Oswaldo Cruz. 1991; 86(Suppl 2):137s-9s.

20. Rosaneli CF, Bighetti AE, Antônio MA, Carvalho JE, Sgarbieri VC. Efficacy of a whey concentrate on the inibition of stomach ulcerative lesions caused by ethanol ingestion. J Medic Food. 2002; 5(4):221-8
21. Morimoto Y, Shimohara K, Oshima S, Takayuki S. Effects of the new anti-ulcer agent KB-5492 on experimental gastric mucosal lesions and gastric mucosal defensive factors, as compared to those of teprenone and cimetidine. Japan J Pharmacol. 1991; 57(4):495-505.

22. Robert A. Cytoprotection by prostaglandins. Gastroenterol. 1979; 77:761-7.

23. Levine RJ. A method for rapid production of stress ulcers in rats. Peptic Ulcer. 1971; 92-7.

24. Stat Soft. Statistic for windows. Computer program manual. Tulsa (OK): Statsoft Inc; 1995.

25. Gonzáles-Tello P, Camacho F, Jurado E, Páez MP, Guadix EM. Enzymatic hydrolysis of whey proteins: II. Molecular weight range. Biotechnol Bioeng. 1994; 44:529-32.

26. Pacheco MTB, Amaya-Farfan Jaime, Sgarbieri VC. Partial characterization of a whey protein concentrate and its enzyme hydrolysates. J Food Biochem. 2002; 26:327-38.

Recebido em: 12/5/2004

Versão final reapresentada em: 14/6/2005 Aprovado em: 8/7/2005 